\title{
Methods of developing digital maturity models for manufacturing companies
}

\author{
M.V. Kupriyanova ${ }^{1,}{ }^{*}$, E.N. Evdokimova ${ }^{1}$, I.P. Solovyova ${ }^{1}$, and I.P. Simikova ${ }^{1}$ \\ ${ }^{1}$ Ryazan State Radio Engineering University, 59/1, Gagarina Str., Ryazan, 390005, Russia
}

\begin{abstract}
The research is aimed at analyzing the existing models of digital maturity. The literature review shows that there is scarce information about the theoretical and methodological basis for differentiation of the maturity levels. Most of the evaluation approaches are focused either on digital readiness, or the digital dividends and road mapping. There is a necessity for developing a comprehensive approach to maturity measurement. Hierarchy analysis is proposed as a useful tool for evaluating digital maturity in manufacturing companies. Free software has made the method acceptable in practice. Hierarchy models have been developed for several manufacturing companies to evaluate the digital maturity score and to analyze possible managerial strategies of digitization.
\end{abstract}

\section{Introduction}

At present, the problem of developing digital maturity models is urgent for manufacturing companies. As the literature review shows, there are various approaches to understanding the process of evaluating maturity levels. The notion of maturity has been thoroughly described in research [1], ISO/IEC 15504, ISO 27001, and other ISO management systems [2]. The discussion of the digital maturity process is interrelated with the development of business process maturity models (BPMMs) and capability maturity models (CMMs) [3] where maturity is understood as a qualitative prerequisite of a process indicating its capability to achieve a higher level of development. Digital maturity measures the level of adopting digital technologies and the degree of transformation of the business model.

Numerous studies propose methods of evaluating digital maturity levels [4,5] relying on the comparison of a companies state of digitization with an archetype. Review of recent research shows that scientists analyze the maturity level by measuring the capability of a company to adopt digital technologies [6,7], and describe digital readiness rather than the static level of maturity. Digital readiness and digital impact of the emerging technologies on the output of a company are proposed as symptoms of maturity [8] and may be used in a twodimensional analysis of clusters without differentiation of particular levels or archetypes of

\footnotetext{
* Corresponding author: mvkupriyanova@gmail.com
} 
maturity. Several research works include instruments of road mapping the digitization process on the basis of comparative analysis $[9,10]$. Thus, the levels of maturity are often evaluated not only as characteristics of an achieved state of digitization. They are often measured in terms of potential (digital readiness) and impact (digital dividends). Numerous prerequisites (hundreds in some studies) are compared to an ideal or a de facto maximum level of digitization, and the indicators are calculated as arithmetic or geometric mean of the prerequisites' values. Several original approaches, as the cluster analysis of Remane et al., or Lucato et al.vector analysis, are more theoretical and need to be validated. Despite the fact that digital maturity models are widely discussed in scientific studies, there is scarce information about the practical application and evaluation of the output of using these models in manufacturing companies. The methods of acquiring the raw data for the maturity analysis, as well as the approaches to constructing the indexes and differentiating the levels of maturity, have certain limitations and remain challenging as objects of studies.

\section{Materials and methods}

The problem of evaluating the level of digital maturity is that a complex assessment includes not only qualitative parameters from statistics or financial documents. It has to rely on the opinion of experts who may have different levels of competency in the sphere of digital transformation. The significance of factors and prerequisites may vary in different economic sectors. Socio-economic and technological barriers or enablers, the digital dividends received by the socio-economic macrosystem (not only by the company itself) should be taken into account in the process of measuring maturity. These specific features of the digital maturity measurement make it possible to apply the hierarchy analysis method of Thomas Saaty [11]. The realization of the method is now given in a number of free-ware decisions, such as Emperor 3.0, a decision support system. The advantage of the method is that it makes it possible to decompose the process of evaluation into several minor hierarchies, or clusters, with specific factors evaluated by different experts. Information technologies make the algorithm of calculations simple, and, what is more important, serve as managerial instruments to choose the regulative measures and strategies, both at the level of governments and company owners.

According to the aim of evaluation, the basic hierarchy may be constructed in different ways. Figure 1a shows the hierarchy model of the digital maturity evaluation in case the researcher aims at differentiating the quality of management and the corresponding maturity levels. The taken example is differentiation into the five levels of capability maturity of a process: initial, managed, defined, quantitatively managed, or optimizing. The parameters may be grouped into clusters of factors and weighted according to their significance.

The hierarchy model in figure $1 \mathrm{~b}$ results in differentiating not only the levels of maturity but also the expectations of the management team about the digitization impact. The environmental factor may be analysed in terms of the existing enablers and barriers of the socio-economic surrounding. These may have different significance for a particular company. Additional levels may be added for short term and long term scenarios of development, for example, for the strategic or financial factors. 


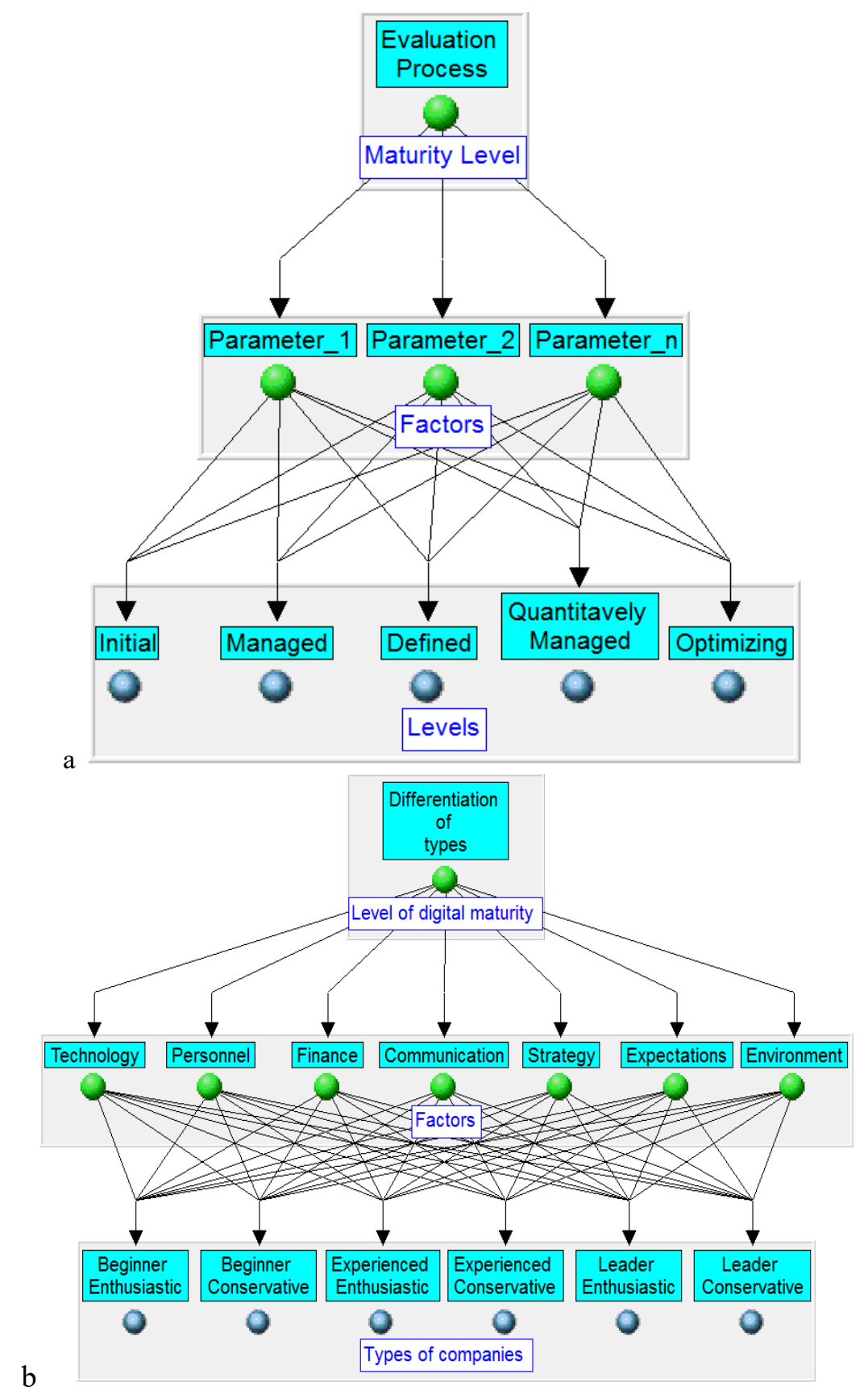




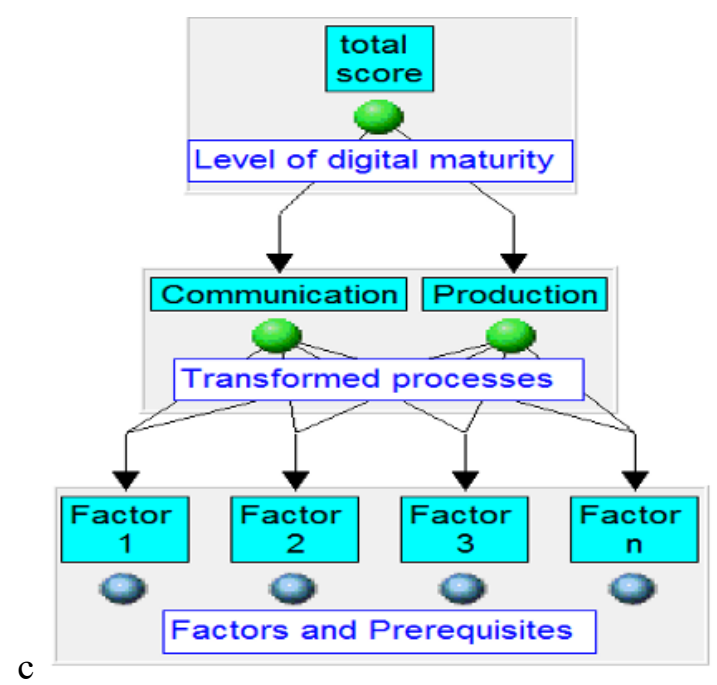

Fig. 1. Variants of hierarchy models for the process of digital maturity evaluation: a - with differentiation of the maturity levels according to the quality of management; $b$ - with differentiation of company types according to their digital maturity and expectations; $\mathrm{c}$ - resulting in calculation of the total digital maturity score.

The upper level of the hierarchy in figure 1c represents the total score from 0 to 1 that a particular company has reached. The second level of the hierarchy may include the spheres S1, S2, ...Sk that experience the influence of the factors and that add to a higher or a lower score of the digital maturity M1, M2,...Mk. In the given example these are the spheres of the production process and the communication. The third level of the hierarchy is comprised of the factors that influence the total score of the maturity level F1, F2, ...Fm. It may be accepted that the score of digital maturity functionally depends on the intensity of the realization of the factors $\mathrm{I}(\mathrm{F} 1), \mathrm{I}(\mathrm{F} 2), \ldots \mathrm{I}(\mathrm{Fm})(1)$ :

$$
M_{j}=f_{j}\left(I\left(F_{1}\right), I\left(F_{2}\right), \ldots, I\left(F_{m}\right)\right),
$$

where $f_{j}\left(X_{1}, X_{2}, \ldots, X_{m}\right)$ is a function of real variables $X_{1}, X_{2}, \ldots, X_{m}$. Then it may be supposed that a zero intensity results in a zero maturity score, that is $f_{j}(0,0, \ldots, 0)=0$. According to the rules of differential calculus an approximate equation is correct (2):

$$
f_{j}\left(X_{1}, X_{2}, \ldots, X_{m}\right) \approx \frac{d f_{j}}{d X_{1}} X_{1}+\frac{d f_{j}}{d X_{2}} X 2+\ldots+\frac{d f_{j}}{d X_{m}} X_{m},
$$

Then it may be accepted that the approximate dependence of the digital maturity score from the intensity of the factors may be taken as a linear function (3):

$$
M_{j} \approx N_{1 j} I\left(F_{1}\right)+N_{2 j} I\left(F_{2}\right)+\ldots+N_{m j} I\left(F_{m}\right)
$$

where $I\left(F_{1}\right), I\left(F_{2}\right), \ldots, I\left(F_{m}\right)$ are the expected levels of intensity of the factors realization;

$N_{1 j}, N_{2 j}, \ldots, N_{m_{j}}$ are positive numbers.

For each $\mathrm{j}$ let $\Delta j$ correspond to the digital maturity score referred to a particular sphere $\mathrm{Sj}$ with the maximum intensity of the corresponding factors. Then (3) may be written as (4): 


$$
M_{j} \approx\left(\Delta_{1} / I j_{1_{2 j} j_{m j}}{ }_{m_{\max }}\right.
$$

where Imax is the maximum intensity, and for each $\mathrm{j}$ the total sum of positive numbers wij is equal to 1 . In this case, wij may be interpreted as a weight of the influence of a factor. The weights can be evaluated by experts when they are comparing pairs of factors. The weights may be evaluated at the scale from 0 to 1 .

Thus, the process of evaluating the digital maturity score includes three steps: factor identification and expert evaluation of their intensity; qualitative prerequisits of the changes in the analysed spheres (for example, production and communication); evaluation of total digital maturity score as a sum of the score added by the evaluated digitization of the spheres $\mathrm{Sj}$. This approach makes it possible to evaluate the expected return on investments and the total impact of digitization. If the model indicates a strong intensity of influence that a particular factor $\mathrm{Fj}$ has on the maturity score, regulative measures can be made to strengthen this factor, and $\mathrm{Cj}$ is the cost of these measures. The maturity score $\mathrm{M}$ may be taken as a function of costs $\mathrm{M}(\mathrm{C} 1, \mathrm{C} 2, \ldots, \mathrm{Cm})$. Then the efficiency of the regulative measures may be taken as a $\Delta M$, a growing score of the digital maturity level.

\section{Results and discussion}

A survey of 15 manufacturing companies was carried out to evaluate their digital maturity levels with the proposed hierarchy analysis method. The data was obtained from open sources of statistics and a questionary about the digital technologies implemented in the operation processes and their impact on revenue, competitiveness, and productivity. Each company was evaluated by several (2-4) experts of the top management and the technical specialists. The decision support system Emperor 3.0 made it possible to reveal the cases of low opinion concordance and to verify the answers of the experts by detailed explanations and additional questions to clarify the conflicting assessments. The experts compared the digital technologies from the point of view of their influence on production and communication. Table 1 illustrates the difference in expert opinion in one of the companies.

Table 1. Experts opinions about the influence of digital technologies on the communication processes in a manufacturing company.

\begin{tabular}{|l|c|c|c|}
\hline & $\begin{array}{l}\text { Expert } \\
1\end{array}$ & $\begin{array}{l}\text { Expert } \\
2\end{array}$ & $\begin{array}{l}\text { Expert } \\
3\end{array}$ \\
\hline Web site optimized for mobile devices & 0,021 & 0,08 & 0,1 \\
\hline $\begin{array}{l}\text { Corporate resources in social networks (and their usage } \\
\text { for communication, consultation and advertizing) }\end{array}$ & 0,045 & 0,121 & 0,164 \\
\hline $\begin{array}{l}\text { Real time information about goods availability, order } \\
\text { status, date of delivery }\end{array}$ & 0,159 & 0,133 & 0,092 \\
\hline Online feedback from the clients & 0,192 & 0,197 & 0,153 \\
\hline Client database and its integration in CRM & 0,193 & 0,201 & 0,312 \\
\hline $\begin{array}{l}\text { Group and project platforms in communication with } \\
\text { clients }\end{array}$ & 0,091 & 0,117 & 0,085 \\
\hline $\begin{array}{l}\text { Knowledge and information exchange among staff } \\
\text { members via group and project platforms, via web and } \\
\text { video conferencing }\end{array}$ & 0,299 & 0,151 & 0,094 \\
\hline
\end{tabular}


Digital technologies for the production process included artificial intelligence, cloud technologies (computation, data storage), big data and advanced analytics, IoT, RFID, digital modelling of the technological process, additive technologies, robots, augmented reality, unmanned vehicles and drones, blockchain, system and equipment connection to the IT infrastructure and business processes, digital design. The experts indicated the usage of these technologies and their influence on the output. The most urgent directions of digitization include safe data storage and transmission ( $60 \%$ of the respondents). Although the impact of digitization is evaluated as more positive than negative (in $42 \%$ of the responses), the share of revenue that the company is ready to invest in digital technologies is less than $10 \%$ in $38 \%$ of the manufacturers.

In the course of analysis the final digital maturity score was calculated (figure 2).

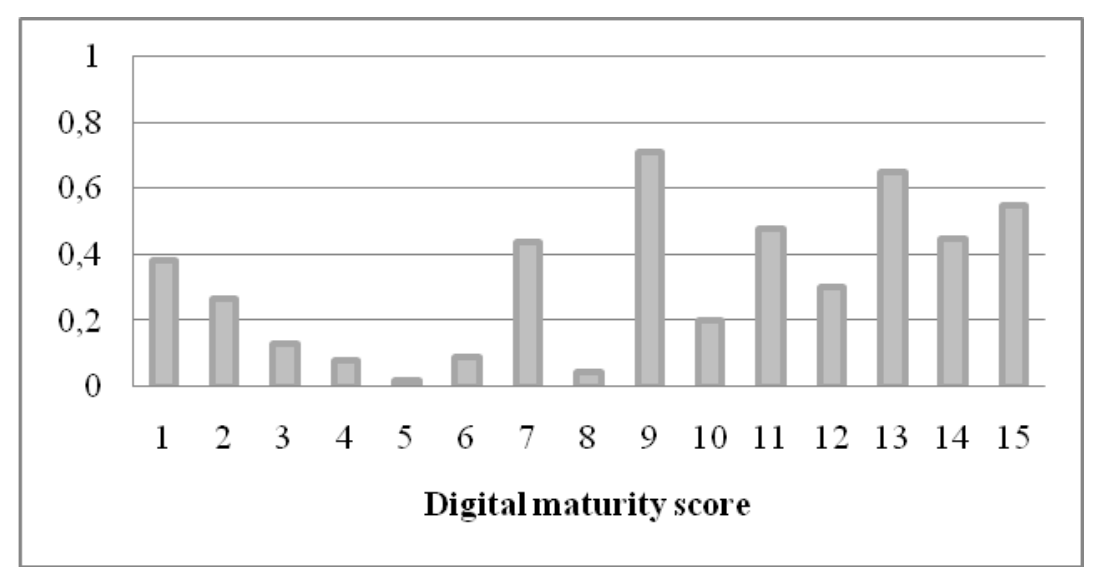

Fig. 2. The results of the hierarchy analysis of the digital maturity levels for the 15 manufacturing companies under research.

The research revealed a mostly conservative attitude to the process of adopting emerging technologies in the production process. Digital readiness is in this case evaluated not only from the technological aspect but also with respect to the human factor. At the same time, the hierarchy analysis makes it possible to take into account the experts' competency, controversy in their opinions, the specific type of the business model and the production process.

\section{Conclusion}

The research of the existing approaches of measuring the levels of digital maturity shows that the majority of the available instruments do not rely either on a proper theoretical basis or on a well-developed methodology. The proposed usage of the hierarchy analysis method has the advantage of adaptive criteria and measurements. Both qualitative and quantitative prerequisites may be considered within a comprehensive frame of evaluation.

The results of our study prove the idea that it is necessary to implement an agile approach to manage the process of digitization successfully. External socio-economic factors, the interests of business owners, the characteristics of a particular economic sector serve as significant factors of digitization and need to be taken into account in the evaluation models. 


\section{Acknowledgements}

The reported study was funded by RFBR, project number 20-010-00219.

\section{References}

1. Tarhan A, Turetken O and Reijers H A 2016 Information and Software Technology 75122 https://doi.org/10.1016/j.infsof.2016.01.010

2. International Organization for Standardization. ISO. 2020 https://www.iso.org/home.html

3. Pulparambil S, Baghdadi Y 2019 Computer Standards \& Interfaces 6165 https://doi.org/10.1016/j.csi.2018.05.001

4. Gileva T 2019 Bulletin USPTU Science, education, economy Series Economy 1(27) 38 https://doi.org/10.17122/2541-8904-2019-1-27-38-52

5. Kupriyanova M V, Simikova I P 2019 Law, Economics and management: Current Issues (Cheboksary: Publishing House Sreda) p 28 https://doi.org/10.31483/r-74149

6. Nick G, Szaller Á, Bergmann J and Várgedő T 2019 IFAC-PapersOnLine 52(13) 289 https://doi.org/10.1016/j.ifacol.2019.11.185

7. Lucato W C, Pacchini A P T, Facchini F and Mummolo G 2019 IFAC-PapersOnLine 52(13) $1808 \mathrm{https} / / /$ doi.org/10.1016/j.ifacol.2019.11.464

8. Remane G, Hanelt A, Kolbe L and Wiesbock F 2017 Proceedings of the 25th European Conference on Information Systems (Guimarães, Portugal) https://www.en.wim.bwl.uni-muenchen.de/pubdb_en/art_proc_i/2017-04.html

9. Schumacher A, Nemeth T and Sihn W 2019 Procedia CIRP 79409 https://doi.org/10.1016/j.procir.2019.02.110

10. Issa A, Hatiboglu B, Bildstein A and Bauernhansl T 2018 Procedia CIRP 72973 https://doi.org/10.1016/j.procir.2018.03.151

11. Saaty T L 2016 The Analytic Hierarchy and Analytic Network Processes for the Measurement of Intangible Criteria and for Decision-Making. Multiple Criteria Decision Analysis (New York: Springer) p 363 https://doi.org/10.1007/978-1-49393094-4_10 